\title{
EDITORIAL
}

\section{Continuous positive airway pressure for asthma: not a big stretch?}

\author{
S. Yim*, J.J. Fredberg ${ }^{\#}$ and A. Malhotra*
}

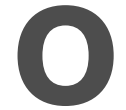
besity increase the risk of both asthma and obstructive sleep apnoea (OSA). By compromising upper airway anatomy, obesity contributes to compromised pharyngeal mechanics and the development of OSA. The mechanisms for how obesity contributes to the development of asthma are less well understood. The association between obesity and asthma, however, is undeniable and to date over 30 articles have shown a relationship between the two [1, 2]. Obesity has effects on both inflammation and airway mechanics, which may be important in asthma. For example, obesity has been associated with increased inflammatory cytokines and adipokines [3]. The role of leptin, a hormone that decreases appetite and increases metabolism, has been of particular interest in obesity and asthma. Obese subjects have increased levels of leptin, suggesting leptin resistance, at least at the level of hypothalamic appetite regulation. Leptin has been found to be pro-inflammatory and in animal models it may increase airway hyperresponsiveness [4,5].

However, the pro-inflammatory effects of obesity are not the only way in which obesity contributes to the development of asthma. The effect of obesity on lung mechanics may be just as or even more important. With obesity, lung volumes (especially functional residual capacity; FRC) decrease as a result of increased abdominal and chest wall pressure. Since airway calibre is a function of lung volume $[6,7]$, obesity contributes to smaller airway calibre. Smaller airway calibre is likely to unload the airway smooth muscle, increase actin-myosin cross-bridging and allow for increased shortening when activated $[8,9]$. Deep breathing has been found to be a potent bronchodilator by periodically stretching the airway smooth muscle and disturbing actin-myosin attachments, making contractions less forceful and the airway more compliant [8]. Obesity also decreases the volume of tidal breathing and, therefore, is likely to decrease the tidal stresses on airway smooth muscle, which allows the muscle to become stiff and hyperresponsive [8].

Like obesity, the supine position also decreases lung volumes (especially FRC) and may have similar effects on airway

*Divisions of Sleep Medicine and Pulmonary and Critical Care Medicine, Brigham and Women's Hospital, and ${ }^{\#}$ Program in Molecular and Integrative Physiological Sciences, Department of Environmental Health, Harvard School of Public Health, Boston, MA, USA.

STATEMENT OF INTEREST: None declared.

CORRESPONDENCE: S. Yim, Divisions of Sleep Medicine and Pulmonary Critical Care Medicine, Brigham and Women's Hospital, 75 Francis St, Boston, MA 02215, USA. Fax: 16177327337. E-mail: syim@partners.org smooth muscle hyperresponsiveness. Nocturnal asthma has been a well-recognised phenomenon, with as many as $74 \%$ of asthma patients being awakened by symptoms at least once a week [10]. Although the pathophysiology of nocturnal asthma is not well understood, the decrease in FRC in subjects with asthma seems to partially contribute to the increase in nocturnal airway resistance [11]. By increasing supine lung volumes and tonic stretch of airway smooth muscle, continuous positive airway pressure (CPAP) appeared to be a promising therapeutic modality to treat nocturnal asthma. Unfortunately, while nocturnal CPAP increases end-expiratory lung volumes, it has not been shown to improve forced expiratory volume in one second (FEV1) in non-OSA asthma subjects [12].

However, in patients with sleep apnoea and concomitant asthma, application of CPAP may be more promising. If both obesity and the supine position cause decreases in lung volume that promote bronchial hyperresponsiveness, then treatment with CPAP may be of benefit. Furthermore, periods of apnoea, as observed in OSA, are likely to worsen bronchial hyperreactivity since fluctuations in transpulmonary pressure are low during airway occlusion. Without substantial fluctuations in lung volumes, tidal stresses on airway smooth muscle may be lost, causing the lung to be "trapped" at a lower lung volume, which may in turn promote actin-myosin crossbridging [13]. In addition, markedly negative intra-thoracic pressures are likely to promote reflux into the oesophagus by creating a pressure gradient favouring acid translocation from the stomach. Treatment with CPAP has been shown to ameliorate gastro-oesophageal reflux disease (GERD) in subjects with OSA [14]. Therefore, treatment of OSA with CPAP in patients with concomitant asthma may have the additional benefit of improving asthma symptoms and bronchial hyperresponsiveness.

In the current issue of the European Respiratory Journal, LAFOND et al. [15] have set out to answer the question: does CPAP improve asthma in patients with OSA? Although LAFOND et al. [15] did not find that CPAP improved bronchial hyperresponsiveness (as measured by the provocative concentration causing a $20 \%$ fall in FEV1 (PC20) to methacholine challenge) or FEV1, quality of life specific to asthma was improved. This finding is similar to a previous study by CIFTCI et al. [16], who found that CPAP in OSA patients with uncontrolled nocturnal asthma did not improve FEV1 but improved asthma night-time symptom scores. Interestingly, both studies showed improvement in subjective measures of asthma symptoms without improvements in objective data, such as the FEV1 or PC20. There may be several explanations for these findings. 
First, the intriguing study by LAFOND et al. [15] consisted of a small number of subjects and lacked a control arm. It is a controversial issue whether withholding treatment of sleep apnoea in a control arm is ethical; therefore, many OSA studies have lacked a control arm. The improvement in asthma symptoms reported by the study's subjects may have represented a placebo effect. Alternatively, without a control arm, this study may have underestimated the effects of CPAP. In a study by LIN et al. [17], 16 adult asthma subjects were randomised to $8 \mathrm{cmH}_{2} \mathrm{O}$ of CPAP or sham CPAP 10 min prior to a methacholine challenge test. Subjects who received CPAP showed an increase in PC20, suggesting decreased airways hyperresponsiveness. However, the control group had a decrease in PC20. Furthermore, response to $\beta$-agonist was also improved in the CPAP arm. Without a control arm, the study by LAFOND et al. [15] may have missed whether subjects with untreated sleep apnoea had worsening of their asthma. Furthermore, by limiting the analysis to patients adherent with CPAP, the authors may have been biased towards including the healthiest participants, e.g. those likely to take their inhaled steroids.

Secondly, how lung function is typically measured may alter the results of the study. For example, one could argue that the deep inspiration prior to exhalation in measuring the FEV1 may dilute the effects of CPAP. That is, the deep inspiration that is required for spirometric measurements may markedly reduce the bronchoconstriction that is being assessed [13]. Furthermore, measurements of FEV1, without taking into account the changes in body position, may underestimate the effect of CPAP on the FEV1. A recent study by MEINERO et al. [18] has demonstrated that position matters when measuring methacholine challenge tests in the sitting versus supine position. They found that FRC decreased by $1 \mathrm{~L}$ from the sitting to the supine position in all subjects. On different days, they administered methacholine in the supine or sitting position and then measured lung function in the supine or sitting position. Interestingly, after administering methacholine in the supine position and measuring the FEV1 in the sitting position, results were similar to the control day (when subjects were sitting for both the methacholine and lung function measurements). However, after administering methacholine and measuring lung function in the supine position, bronchial hyperresponsiveness was increased when compared with the control day. Thus, bronchial responsiveness may be position dependent, which is likely to be mediated via changes in end-expiratory lung volume.

Thirdly, CPAP may not be enough to disturb actin-myosin cross-bridging. Bi-level positive airway pressure may be required to induce more dynamic changes in lung volume and increase tidal stresses on airway smooth muscle. Although CPAP may be the treatment of choice for OSA, it might not provide full therapeutic benefits for asthma.

Finally, CPAP may do more than improve lung volume. Nocturnal asthma physiology is complex and may reflect the effect of circadian changes in hormones, lung mechanics in the supine position, inflammatory cytokines and the effect of GERD among others. Changes in FEV1 may not represent all that is occurring. Other measurements, such as histology and measurements of inflammatory cytokines may shed light on how CPAP could be improving symptoms of asthma but not changes in lung function.

It is still too early to say that positive pressure in obstructive sleep apnoea subjects with asthma is ineffective and more studies need to be carried out on this important subject. With the average body mass index increasing in Western countries, more people will be affected by both obstructive sleep apnoea and asthma. Understanding how positive pressure may ameliorate the symptoms of asthma in both obstructive sleep apnoea and non-obstructive sleep apnoea populations may offer other therapeutic options for those who suffer from asthma, and will ultimately help in understanding the pathophysiology of nocturnal asthma.

\section{REFERENCES}

1 Shore SA. Obesity and asthma: implications for treatment. Curr Opin Pulm Med 2007; 13: 56-62.

2 Shore SA, Johnston RA. Obesity and asthma. Pharmacol Ther 2006; 110: 83-102.

3 Fantuzzi G. Adipose tissue, adipokines, and inflammation. J Allergy Clin Immunol 2005; 115: 911-919.

4 Shore SA, Schwartzman IN, Mellema MS, Flynt L, Imrich A, Johnston RA. Effect of leptin on allergic airway responses in mice. J Allergy Clin Immunol 2005; 115: 103-109.

5 Mito N, Kitada C, Hosoda T, Sato K. Effect of diet-induced obesity on ovalbumin-specific immune response in a murine asthma model. Metabolism 2002; 51: 1241-1246.

6 Ding DJ, Martin JG, Macklem PT. Effects of lung volume on maximal methacholine-induced bronchoconstriction in normal humans. J Appl Physiol 1987; 62: 1324-1330.

7 Hughes JM, Hoppin FG Jr, Mead J. Effect of lung inflation on bronchial length and diameter in excised lungs. J Appl Physiol 1972; 32: 25-35.

8 Shore SA, Fredberg JJ. Obesity, smooth muscle, and airway hyperresponsiveness. J Allergy Clin Immunol 2005; 115: 925-927.

9 Fredberg JJ, Inouye DS, Mijailovich SM, Butler JP. Perturbed equilibrium of myosin binding in airway smooth muscle and its implications in bronchospasm. Am J Respir Crit Care Med 1999; 159: 959-967.

10 Turner-Warwick M. Epidemiology of nocturnal asthma. Am J Med 1988; 85: 6-8.

11 Ballard RD, Irvin CG, Martin RJ, Pak J, Pandey R, White DP. Influence of sleep on lung volume in asthmatic patients and normal subjects. J Appl Physiol 1990; 68: 2034-2041.

12 Martin RJ, Pak J. Nasal CPAP in nonapneic nocturnal asthma. Chest 1991; 100: 1024-1027.

13 Fredberg JJ. Frozen objects: small airways, big breaths, and asthma. J Allergy Clin Immunol 2000; 106: 615-624.

14 Green BT, Broughton WA, O'Connor JB. Marked improvement in nocturnal gastroesophageal reflux in a large cohort of patients with obstructive sleep apnea treated with continuous positive airway pressure. Arch Intern Med 2003; 163: $41-45$. 
15 Lafond $\mathrm{C}$, Sériès $\mathrm{F}$, Lemière $\mathrm{C}$. Impact of CPAP on asthmatic patients with obstructive sleep apnoea. Eur Respir J 2007; 29: 307-311.

16 Ciftci TU, Ciftci B, Guven SF, Kokturk O, Turktas H. Effect of nasal continuous positive airway pressure in uncontrolled nocturnal asthmatic patients with obstructive sleep apnea syndrome. Respir Med 2005; 99: 529-534.
17 Lin $\mathrm{HC}$, Wang $\mathrm{CH}$, Yang $\mathrm{CT}$, et al. Effect of nasal continuous positive airway pressure on methacholineinduced bronchoconstriction. Respir Med 1995; 89: 121-128.

18 Meinero M, Coletta G, Dutto L, et al. Mechanical response to methacholine and deep inspiration in supine posture in men. J Appl Physiol 2006; [Epub ahead of print PMID: 16959912]. 